\title{
EXPANSÃO DO ENSINO SUPERIOR E PRECARIZAÇÃO DO TRABALHO DOCENTE: o trabalho do "horista" no ensino privado
}

\author{
EXPANSION OF HIGHER EDUCATION AND INSECURITY TEACHING JOB: the \\ "hourly" job in private education
}

EXPANSIÓN DE LA ENSEÑANZA SUPERIOR Y LA PRECARIZACIÓN DEL TRA-
BAJO DOCENTE: el trabajo de los asalariados "por hora" en la educación privada

Walkiria Martinez Heinrich Ferrer Professora Doutora da Universidade de Marília (UNIMAR) walkiriamf@terra.com.br nipex@unimar.br

Marisa Rossignoli Professora Doutora da Universidade de Marília (UNIMAR) mrossinholi@uol.com.br

\begin{abstract}
RESUMO: No contexto do processo de globalização e da consequente reestruturação produtiva do capital, podemos visualizar um aspecto que pode ser considerado positivo, ou seja, a valorização da educação como uma das condições indispensáveis para o desenvolvimento econômico do país. Não obstante, verifica-se uma precarização das relações de trabalho dos docentes no ensino superior, de forma expressiva no trabalho do docente horista das instituições privadas de ensino superior, categoria que representa a maioria dos assalariados da área educacional. A precarização do trabalho docente se estende também à questão salarial com a "flexibilização" dos contratos trabalhistas, sendo uma característica específica do momento atual, pois essa flexibilização se verifica no cenário trabalhista como um todo, atingindo praticamente todas as categorias. A intensificação do trabalho docente estende-se também a questão da "produtividade", ou seja, o quanto o docente produz em termos de aulas ministradas, orientações concluídas e em andamento, publicações (em periódicos com Qualis/CAPES de expressão no meio acadêmico) dentre outras determinações de caráter quantitativo. Portanto, a análise sobre o universo dos trabalhadores da educação, especificamente o docente horista, torna-se de extrema importância, não somente em razão da depreciação salarial, como também pela excessiva jornada de trabalho, depreciação das condições físicas e emocionais e necessária regulamentação dessa categoria de trabalho docente.
\end{abstract}

PALAVRAS-CHAVE: Trabalho docente. Relações de trabalho. Mercantilização da educação.

ABSTRACT: In the context of globalization and consequent productive restructuring of capital, we can see an aspect that considered positive, that is to say, valuing education as one of the indispensable conditions for the country's economic development. Nevertheless, precariousness in working conditions of higher education professors' is evident, especially with hourly professors at private institutions. This is a category that represents the majority of employees in the education sector. Precariousness of teaching work also extends to the salary issue with the "flexibility" of the labor contracts with one current particular feature because this flexibility can be seen in the labor scenario as a whole, reaching virtually every category. The intensification of teaching work also extends to the issue of "productivity", how much the professor produces in terms of the classes, completed guidelines and ongoing publications (in journals with Qualis / CAPES expression in academia) among other quantitative determinations. Therefore, analysis of the world of education workers, specifically hourly professors, becomes extremely important, not only because of wage depreciation, but also excessive working hours, depreciation of physical and emotional conditions and necessary regulation in this teaching category.

KEYWORDS: Professor's work. Labor relations. Commodification of education.

Artigo recebido em setembro de 2016

Aprovado em novembro de 2016 
RESUMEN: En el contexto de la globalización y la consecuente reestructuración productiva del capital, podemos ver un aspecto que se puede considerar positivo, es decir, la valorización de la educación como una de las condiciones indispensables para el desarollo económico del país. Sin embargo se comprueba una precarizacíon de las relaciones laborales de los profesores de educación superior, de manera expresiva en el trabajo de los que ganan por hora en las instituciones privadas de educación superior, una categoría que representa a la mayoría de los empleados en el área educacional. La precarización del trabajo de enseñanza se extiende también a la cuestión salarial con la "flexibilidad" de los contratos de trabajo, es una característica específica del momento presente, ya que esa flexibilización se encuentra en el escenario laboral como un todo, alcanzando prácticamente casi todas las categorías. La intensificación del trabajo docente se extiende también a la cuestión de la "productividad", es decir, cuánto el docente produce en términos de clases impartidas, orientaciones concluidas y en curso, publicaciones (en periódicos con Qualis/ CAPES de expresión en el ámbito académico), entre otras determinaciones de carácter cuantitativo. Por lo tanto, el análisis sobre el universo de los trabajadores de la educación, en particular el docente asalariado por hora, se torna extremamente importante, no solamente en razón de la depreciación de los salarios, así como por una jornada laboral excesiva, depreciación de las condiciones físicas y emocionales y la necesaria reglamentación de esta categoria de trabajo docente.

PALABRAS CLAVE: Trabajo docente. Relaciones de trabajo. Mercantilización de la educación. 
EXPANSÃO DO ENSINO SUPERIOR | Walkiria Martinez Heinrich Ferrer e Marisa Rossignoli

\section{1 | INTRODUÇÃO}

A década de 1970 representou um período de profundas transformações no cenário político, econômico e social dos países inseridos no chamado processo de globalização. Como resposta à crise do capital, com a queda da lucratividade do próprio sistema capitalista, foi preciso reestruturar o processo produtivo, numa tentativa de resgatar a prosperidade verificada em décadas passadas. A orientação política sofreu alterações e diversos setores tiveram que se adaptar às novas condições do mercado.

Viabilizadas por um programa de governo neoliberal, nesse contexto surgem denominações como privatizações, estabilidade monetária, hegemonia cultural, cidadania global, e destaca-se na presente análise, a chamada reestruturação produtiva do capital.

No contexto do processo de globalização podemos visualizar um aspecto que pode ser considerado positivo, ou seja, a valorização da educação como uma das condições indispensáveis para o desenvolvimento econômico do país. No momento atual a educação, ainda que sua reestruturação esteja voltada ao campo empresarial, deixou de ocupar a posição de prioridade secundária nas reformas políticas e nas aspirações da sociedade civil.

Organismos internacionais ressaltaram a importância da educação como fator principal do desenvolvimento de uma nação. O conteúdo das propostas do Banco Mundial para uma reforma no sistema educacional brasileiro enaltece o papel da educação na nova ordem mundial, tendo em vista as transformações decorrentes da evolução tecnológica. ${ }^{1}$

No bojo do chamado processo de globalização, a educação sofre uma interferência direta da mundialização do capital financeiro. A reestruturação econômica, tanto dos países líderes em desenvolvimento quanto das chamadas economias "emergentes", impõe novas determinações ao campo educacional, em especial ao ensino superior, conferindo-lhe novos papéis a serem desempenhados na nova ordem mundial. Em decorrência deste contexto, juntamente com a reestruturação econômica dos países inseridos no processo, ocorre uma reestruturação do universo do ensino superior, gerada por sua aproximação com o processo produtivo capitalista.

\section{1| REESTRUTURAÇÃO PRODUTIVA DO CAPITAL}

Sob orientação keynesiana o sistema capitalista apresentou elevados índices de crescimento, principalmente no período pós-guerra. Com a crise do capital, verificada na década de 1970, principalmente nas grandes potências da época, Estados Unidos e Japão, inaugura-se a chamada mundialização do capital financeiro, ou de capital rentista ou "fictício". A lógica do capital se manifesta de uma forma distinta daquela observada após a Revolução Industrial, em que havia a reprodução dos meios materiais de produção: D-M-D' (Dinheiro-Mercadoria-Dinheiro). A mundialização do capital se desenvolve por meio da reprodução do capital financeiro, do capital rentista: D-D' (Dinheiro-Dinheiro).

Durante as décadas de 1970/1980 houve uma intensificação do capital rentista ou financeiro, expansão viabilizada pelos avanços tecnológicos, principalmente da rede mundial de computadores. A extrema rapidez com que se desenvolveu a comunicação informatizada propiciou uma instantaneidade das operações financeiras, com a possibilidade de negociação de grandes volumes de capitais "fictícios" entre diferentes e distantes mercados, em tempo real. Segundo Giovanni Alves, a rede mundial de computadores - Internet - constitui o arcabouço midiático da financeirização:

1 BANCO MUNDIAL. Prioridades y Strategias para la Educación, Banco Mundial, 1995. 


\begin{abstract}
O desenvolvimento do ciberespaço na última década do século XX é um produto legítimo - e avançado - da Terceira Revolução Científico- -Tecnológica. Ele é um dos importantes avanços no campo da comunicação informatizada, ou telemática, a partir dos anos 80 que contribuiu para impulsionar a mundialização do capital. Na verdade, a Internet se constituiu no arcabouço midiático de uma nova etapa do capitalismo mundial, cuja principal característica é o predomínio da financeirização. (Alves, 1999, p. 169).
\end{abstract}

No contexto do capitalismo flexível ou capitalismo neoliberal, sob a dominância do capital financeiro, a consequência lógica foi um processo de intensificação da reestruturação produtiva do capital e também como consequência, a intensificação da precarização do trabalho.

$$
\begin{gathered}
\text { Capitalismo neoliberal } \Rightarrow \text { capital financeiro } \Rightarrow \text { reestruturação produtiva do capital } \\
\text { PRECARIZAÇAO DO TRABALHO }
\end{gathered}
$$

A reestruturação da empresa capitalista, como uma das respostas à crise da acumulação do capital no início da década de 1970, visava à obtenção de um maior lucro sem aumentar o número de trabalhadores. "Novos processos de trabalho emergem, onde o cronômetro e a produção em série e de massa são 'substituídos' pela flexibilização da produção, pela 'especialização flexível', por novos padrões de busca de produtividade, por novas formas de adequação de produção à lógica do mercado. " (ANTUNES, 1999, p. 16).

A utilização maciça de tecnologias avançadas no processo produtivo provocou a transformação do trabalho especializado, em que o operário exercia tarefas limitadas, em trabalho polivalente, em que o operário pode operar várias máquinas ao mesmo tempo. $O$ trabalho individualizado passa a ser exercido por uma equipe, no qual um grupo de trabalhadores opera um sistema de máquinas automatizadas. A produção em série e em massa do modelo fordista/taylorista foi substituída pela produção pela demanda, ou seja, se produz o que o mercado necessita no momento, com a formação de um estoque mínimo. Utiliza-se o sistema kanban, no qual os produtos são repostos quando saem das prateleiras, minimizando os estoques. Também há uma preocupação com o controle do tempo de produção, incluindo armazenagem e transporte, e a qualidade do produto final, expressa pelo sistema just in time e pelos Círculos de Controle de Qualidade (CCQs).

Originadas das novas condições do trabalho advindas do toyotismo, podemos ressaltar as qualificações "intelectuais", ou seja, segundo Giovanni Alves:

[...] o toyotismo tende a exigir, para o seu desenvolvimento como nova lógica da produção capitalista, novas qualificações do trabalho que articulam habilidades cognitivas e habilidades comportamentais. Tais novas qualificações são imprescindíveis para a operação dos novos dispositivos organizacionais do toyotismo e da sua nova base técnica (a automação flexível). São elas que compõem a nova subsunção real do trabalho ao capital (subsunção formal-intelectual ou espiritual). (ALVES, 2007, p.248).

A flexibilização do processo produtivo reflete no mundo do trabalho com a flexibilização das relações trabalhistas, que são forçadas a acompanhar e se adaptar às inovações tecnológicas, com a alteração das relações contratuais. No novo contexto, a integração vertical do modelo fordista, em que as diversas etapas de montagem eram realizadas na própria empresa, foi substituída pela chamada horizontalização ou terceirização do processo produtivo, que consiste no repasse de determinadas fases da produção aos serviços de terceiros. Esta subcontratação de serviços externos ao quadro funcional da empresa debilita a organização dos trabalhadores, acentuando a precarização 
e informalidade do trabalho, por meio dos contratos provisórios que limitam os direitos trabalhistas.

A reestruturação produtiva do capital interfere diretamente nas relações de trabalho, não apenas a nível contratual, mas essencialmente nas novas condições determinadas pela atual conjuntura econômica, um novo perfil de trabalhador passa a ser exigido. Segundo Ana Teixeira: "A racionalidade da produção e sua exigência por desregulamentação e flexibilização do mercado de trabalho seriam argumentos suficientes para justificar as mudanças na dinâmica do emprego, nos perfis ocupacionais e nos requisitos de qualificação impostos aos trabalhadores". (TEIXEIRA, 1998, p. 163).

Com a associação/articulação da gestão toyotista e a utilização de novas tecnologias informacionais a precarização do trabalho não se resume à questão salarial, ou seja, a "degradação" das relações e condições de trabalho leva ao conceito de "precarização do trabalho", que, segundo Giovanni Alves não se resumeaoaspecto salarial, ou seja, depreciaçãoem termos decompensaçãofinanceira.

[...] a precarização do trabalho no século XXI, não se reduz apenas a precarização salarial, com a constituição da nova precariedade salarial caracterizada, por exemplo, pela regulação salarial precária, gestão toyotista e novas tecnologias informacionais. No século XXI surgiram novas formas de precarização do trabalho que denominamos (1) precarização existencial, decorrente do modo de vida just in time; que produz vida reduzida e provoca carecimentos radicais nas pessoas- que-trabalham; (2) e a precarização radical do homem como ser genérico, a precarização do homem-que-trabalha, decorrente dos adoecimentos laborais. (ALVES, 2014, p. 18).

Diante das transformações estruturais do fator "trabalho", tornou-se necessário o incremento numa área que até então não se destacava no cenário político e econômico do país. A área educacional passa a ser vista como a responsável pela adequação e capacitação do mercado de trabalho, contribuindo decisivamente para o desenvolvimento econômico do país:

É nesse contexto que os investimentos em educação vão assumindo o lugar de poderoso 'remédio', enquanto condição necessária e central para a formação de uma força de trabalho qualificada, capaz de possibilitar a inserção competitiva do país no mercado mundial e, assim, favorecer a superação da pobreza e do subdesenvolvimento. (TEIXEIRA, 1998, p. 163).

Assim que, diante das novas determinações do toyotismo, busca-se a otimização do trabalho, especificamente do trabalho docente espera-se a intensificação de novas habilidades cognitivas e comportamentais.

\section{2| A REESTRUTURAÇÃO PRODUTIVA E A EDUCAÇÃO SUPERIOR: POLÍTICAS GOVER- NAMENTAIS DE ACESSO AO ENSINO SUPERIOR}

A reestruturação produtiva do capital, tanto dos países líderes em desenvolvimento quanto das chamadas economias "emergentes", impõe novas determinações ao campo educacional, em especial ao ensino superior, conferindo-Ihe novos papéis. Em decorrência deste contexto, juntamente com a reestruturação econômica dos países inseridos no processo, ocorre uma reestruturação do universo do ensino superior, gerada por sua aproximação com o processo produtivo capitalista.

A atual conjuntura econômica pressupõe uma mão de obra capaz de acompanhar a demanda gerada pelas transformações do processo produtivo, sendo mais flexível às inovações tecnológicas e às novas determinações impostas pelo mercado de trabalho: "Surgem novos perfis de qualificação de mão de obra. Inteligência e conhecimento parecem ser variáveis-chave para a modernização e a produtividade do processo de trabalho, como também capacidade de solucionar 
problemas, liderar, tomar decisões e adaptar-se a novas situações”. (MELLO, 1997, p. 37).

A questão da qualificação da mão de obra nos remete à precedência, na sociedade atual, do que Frigotto denomina "capital humano", que se configura como "função de saúde, conhecimento e atitudes, comportamento, hábitos, disciplina, ou seja, a expressão de um conjunto de elementos adquiridos, produzidos e que, uma vez adquiridos, geram a ampliação da capacidade do trabalho e, portanto, de maior produtividade". (FRIGOTTO, 1997, p. 92).

Segundo esta concepção, o investimento na formação de "capital humano", por parte dos países subdesenvolvidos, acarreta a formação de mão de obra mais qualificada e, consequentemente, promove um crescimento econômico mais acelerado. Com relação ao crescimento individual propicia uma ascensão social aos que investem em educação e treinamento qualificados.

Portanto, esta necessidade de formação de uma mão de obra que atenda a demanda gerada pelas transformações da reprodução do capital pressupõe uma aproximação dos centros originários de formação de conhecimento, ou seja, as universidades e os institutos de pesquisa, ao processo produtivo. Na "sociedade do conhecimento" são impostas novas determinações à área educacional e, especialmente, ao ensino superior. No contexto da reestruturação capitalista, as "funções", assim como a estruturas administrativa e financeira, das instituições de ensino superior estão sujeitas a sofrer transformações.

No âmbito da nova ordem mundial, o aumento da produtividade e competitividade tornou-se um imperativo para o objetivo da inserção na economia mundial, tanto para os países desenvolvidos economicamente como para aqueles cujas economias estão "emergindo". Neste contexto, o conhecimento assume um grande valor econômico, que se expressa por meio de investimentos na pesquisa aplicada, principalmente em ciência e tecnologia. Esta é uma questão que parece apontar outra tendência deste nível de ensino, ou seja, "[...] a priorização das áreas científicas mais próximas do setor produtivo em detrimento das demais: (...) Já mostram isso as fundações ligadas às instituições de ensino superior prestadora de serviços às empresas industriais e os diversos projetos de parceria entre empresa e universidade existentes. " (SILVA JÚNIOR, 1996, p. 27).

Como exemplo dessa orientação é possível citar o aumento e incentivo de cursos superiores tecnólogos, seja promovido pelo governo federal, estadual ou instituições privadas e o programa realizado pelo governo federal e organismos de fomento à pesquisa, o programa "Ciência sem fronteiras", criado em 26 de julho de 2011:

Ciência sem Fronteiras é um programa que busca promover a consolidação, expansão e internacionalização da ciência e tecnologia, da inovação e da competitividade brasileira por meio do intercâmbio e da mobilidade internacional. A iniciativa é fruto de esforço conjunto dos Ministérios da Ciência, Tecnologia e Inovação (MCTI) e do Ministério da Educação (MEC), por meio de suas respectivas instituições de fomento - CNPq e Capes -, e Secretarias de Ensino Superior e de Ensino Tecnológico do MEC.

O projeto prevê a utilização de até 101 mil bolsas em quatro anos para promover intercâmbio, de forma que alunos de graduação e pós-graduação façam estágio no exterior com a finalidade de manter contato com sistemas educacionais competitivos em relação à tecnologia e inovação. Além disso, busca atrair pesquisadores do exterior que queiram se fixar no Brasil ou estabelecer parcerias com os pesquisadores brasileiros nas áreas prioritárias definidas no Programa, bem como criar oportunidade para que pesquisadores de empresas recebam treinamento especializado no exterior. (PROGRAMA CIÊNCIA SEM FRONTEIRAS, maio, 2015).

Desde sua implantação, o Programa Ciência sem Fronteiras foi responsável pela concessão de 78.173 bolsas de estudos, distribuídas em diferentes modalidades, com a expressiva concessão de bolsas na modalidade "Graduação sanduíche no exterior", com 61.542 bolsas, cerca de $80 \%$ do total. (PROGRAMA CIÊNCIA SEM FRONTEIRAS, 2015). 
Como indicativo da aproximação da educação superior aos centros produtivos, torna-se necessário o detalhamento das áreas prioritárias do Programa Ciência sem Fronteiras, onde a área de Ciências Humanas e Sociais Aplicadas sequer foi contemplada. Os destaques foram para as áreas de Ciências Exatas e Tecnológicas e Ciências Biológicas e da Saúde, atraentes em termos de qualificação profissional, ou melhor, mais próxima do "produto" procurado na atualidade: mão de obra qualificada. Nesse sentido, os dados abaixo demonstram a prevalência das engenharias e áreas tecnológicas, representando $44 \%$ do total de bolsas concedidas.

QUADRO 1 - Distribuição de bolsas implementadas por área prioritária

\begin{tabular}{|l|c|c|}
\hline \multicolumn{1}{|c|}{ Área prioritária da bolsa } & Número de bolsas & $\%$ \\
\hline Engenharias e demais áreas tecnológicas & & $44 \%$ \\
\hline Biologia, Ciências Biomédicas e da Saúde & 34.545 & $18 \%$ \\
\hline Indústria Criativa & 13.723 & $8 \%$ \\
\hline Ciências Exatas e da Terra & 6.431 & $7,8 \%$ \\
\hline Computação e Tecnologias da Informação & 6.171 & $6,2 \%$ \\
\hline Produção Agrícola Sustentável & 4.867 & $3,7 \%$ \\
\hline Biotecnologia & 2.893 & $2,4 \%$ \\
\hline Fármacos & 1.886 & $2 \%$ \\
\hline Biodiversidade e Bioprospecção & 1.635 & $1,5 \%$ \\
\hline Energias Renováveis & 1.159 & $1,2 \%$ \\
\hline Ciências do Mar & 925 & $0,95 \%$ \\
\hline Petróleo, Gás e Carvão Mineral & 731 & $0,80 \%$ \\
\hline Nanotecnologia e novos materiais & 631 & $0,80 \%$ \\
\hline Novas Tecnologias de Engenharia Construtiva & 628 & $0,70 \%$ \\
\hline Não informado & 533 & $0,63 \%$ \\
\hline Tecnologia Aeroespacial & 497 & $0,48 \%$ \\
\hline Tecnologias de Prevenção e Mitigação de Desastres Naturais & 246 & $0,31 \%$ \\
\hline Formação de Tecnólogos & 167 & $0,21 \%$ \\
\hline Tecnologia Mineral & 132 & $0,17 \%$ \\
\hline
\end{tabular}

Fonte: Programa Ciência sem Fronteiras, 2015.

Ainda, como consequência do incentivo governamental à formação de mão de obra qualificada, é possível destacar os programas federais de acesso ao ensino superior, o programa "Universidade para todos" - PROUNI, e "Fundo de Financiamento Estudantil" - FIES, o Sistema de Seleção Unificada - SISU, Programa de Apoio a Planos de Reestruturação e Expansão das Universidades Federais - REUNI, Universidade Aberta do Brasil - UAB, dentre outros.

O objetivo central dos programas governamentais de acesso ao ensino superior atende ao solicitado pelo mercado de trabalho, ou seja, a qualificação profissional de determinados segmentos da população, além do expressivo aumento do número de matrículas na rede privada, acarretado principalmente, pelo PROUNI e FIES.

Somente o PROUNI foi responsável pelo acesso de mais de um milhão de estudantes no nível superior: "O Prouni já atendeu, desde sua criação [2004] ] até o processo seletivo do segundo 
semestre de 2014, mais de 1,4 milhão de estudantes, sendo $70 \%$ com bolsas integrais." Somente nosegundo semestre de 2014, o PROUNI foi responsável pelo ingresso de 115.101 alunos no ensino superior, tendo participação expressiva nos estados de São Paulo, Minas Gerais, Distrito Federal e Paraná. (PORTAL PROUNI, 2015).

Em substituição ao Credito Educativo CREDUC (1976-1998), em 1999 o Governo Federal instituiu o programa "Fundo de Financiamento Estudantil", responsável por grande parte da entrada de jovens no ensino superior. No período de 1999 até 2009 o FIES possibilitou a concessão de 600 mil novos contratos. Esse número, já expressivo, saltou para 1,1 milhão de contratos no período de 2010 a 2013, representando um investimento governamental de 13 bilhões. (FIES, 2015).

Como consequência imediata da política de acesso ao ensino superior verifica-se o aumento do número de matrículas nesse nível de ensino, principalmente nas instituições de ensino superior privado.

O Instituto Nacional de Estudos e Pesquisas Educacionais Anísio Teixeira - INEP disponibiliza para consulta on line relatórios técnicos, onde são disponibilizados dados sobre o ensino superior no país. A análise desse material possibilita a verificação de que as IES privadas tradicionalmente apresentaram um maior número de matrículas representando $74 \%$ das matrículas realizadas no ano de 2013 , em detrimento aos $26 \%$ das IES públicas. (CENSO DA EDUCAÇÃO SUPERIOR, 2013).

Com base nos dados do INEP é possível constatar que o pico de crescimento das matrículas no ensino superior privado coincide com o período dos investimentos do governo federal no ensino superior, precisamente após o ano de 2000, com a instituição do FIES (2.700.000) e em 2004 com o PROUNI, onde apresentou quase o dobro do número de matrículas (4.200.000).

Mas o crescimento das matriculas das IES privadas não configura uma realidade isolada, pois juntamente com o aumento das matrículas verifica-se a acentuação do trabalho docente.

Pela análise dos dados da tabela abaixo é possível constatar a prevalência das matrículas nas IES privadas, tornando mais crítica a desproporção entre número de alunos por docentes: 12 alunos por docente nas IES públicas enquanto que nas IES privadas verifica-se mais que o dobro, 29 alunos por docente.

QUADRO 2 - Número de matrículas ensino superior - 2013

\begin{tabular}{|c|c|c|}
\hline & $\begin{array}{c}\text { IES públicas } \\
\text { (Federal - Estadual e Municipal }\end{array}$ & IES privadas \\
\hline Número de IES & 301 & 2.090 \\
\hline Matrículas graduação & 1.932 .527 & 5.373 .450 \\
\hline Docentes em exercício & 152.166 & 181.302 \\
\hline
\end{tabular}

Elaboração do autor

Fonte: censo MEC/INEP 2013

Essa situação reflete diretamente nas condições de trabalho do docente, a intensificação da jornada, redução salarial e por consequência esgotamento físico e emocional.

\section{3 | A PRECARIZAÇÃO DO TRABALHO DOCENTE/HORISTA}

Nas últimas décadas ficou evidente uma priorização das atividades de ensino superior das instituições privadas em detrimento das IES públicas. Os diferentes programas de incentivo ao acesso no ensino superior, com financiamento governamental, assim como o aumento do número de 
EXPANSÃO DO ENSINO SUPERIOR | Walkiria Martinez Heinrich Ferrer e Marisa Rossignoli

matrículas nas IES privadas, acarretam a denominada "mercantilização" da educação superior, com a intensificação da concepção de compartilhamento da educação superior com a iniciativa privada:

[...] a política voltada para a mercantilização da educação superior tem sido irradiada para toda a América Latina pela atuação do Banco Mundial ao longo da década de 1990 [...]. Desde então, a ideia de que a educação deveria ser encarada como 'Setor dos Serviços Não-Exclusivos do Estado' passou a orientar a ação do Estado em relação às universidades públicas (nos âmbitos federal, estadual e municipal). Uma consequência prática dessa política começou a ser mais propriamente observada por volta da primeira metade da década de 1990, quando a relação de matrículas em cursos presenciais oferecidas por IES privadas e públicas aumentou bastante em favor das primeiras. (BOSI, 2007, p. 1507).

Tal fato reflete diretamente nas condições de trabalho do docente universitário, que tem sua carga de trabalho triplicada com o aumento do número de alunos por docente, pois as funções do docente não se resumem ao período em sala de aula, mas estende-se ao preparo das aulas, correção de provas, organização de material multimídia e, na atualidade, também exerce tarefas antes executadas pelas secretarias das IES, como lançar notas e faltas nos sistemas informatizados.

A precarização do trabalho docente se estende também à questão salarial com a "flexibilização" dos contratos trabalhistas, sendo uma característica específica do momento atual, pois essa flexibilização se verifica no cenário trabalhista como um todo, atingindo praticamente todas as categorias.

Segundo Bosi (2007), surgiram formas "criativas" de contratação docente, sendo meios ou tentativas de conter a deterioração dos salários: 1. Contratos temporários ou até mesmo efetivos, mas com pagamento por hora-aula, ou seja, valor correspondente ao tempo de aula ministrado. Na maior parte das vezes essas relações contratuais ignoram plano de carreira, reduzindo a remuneração ao tempo de trabalho. 2. Bolsa de pesquisa e adicionais por atividades de extensão como forma de remuneração docente. 3. Contratação de docentes "conferencistas", ou seja, por tempo determinado.

\begin{abstract}
Visualizar a totalidade desse processo requer adotar o pressuposto de que, para além da precarização do trabalho docente expresso nas 'velhas' e 'novas' formas de contratação, muitas mudanças foram introduzidas na rotina das atividades de ensino, pesquisa e extensão, desde, pelo menos, o governo Collor de Melo. Do ponto de vista do capital, trata-se de aumentar o trabalho docente em extensão e intensidade. (BOSI, 2007, p. 1511).
\end{abstract}

A intensificação do trabalho docente estende-se também a questão da "produtividade', ou seja, o quanto o docente produz em termos de aulas ministradas, orientações concluídas e em andamento, publicações (em periódicos com Qualis/CAPES de expressão no meio acadêmico) dentre outras determinações de caráter quantitativo.

Como exemplo do caráter quantitativo da produção docente, podemos citar a Plataforma Lattes, ou seja, uma base de dados onde estão disponibilizados currículos, grupos de pesquisa e instituições em um sistema de informações: "O Currículo Lattes se tornou um padrão nacional no registro da vida pregressa e atual dos estudantes e pesquisadores do país, e é hoje adotado pela maioria das instituições de fomento, universidades e institutos de pesquisa do País." (PLATAFORMA LATTES, 2015).

Ao acessar um currículo lattes na base de dados do CNPq é possível verificar a predominância do caráter quantitativo, ou seja, na tela de acesso localizamos os "indicadores de produção" e em seu interior existem dados sobre a produção bibliográfica, produção técnica, orientações concluídas, todas as produções, total de artigos publicados por periódico e total de artigo por co-autor. Com essa base de dados, de consulta pública, é possível quantificar a produção docente. 
Com o processo de mercantilização da educação o "valor" do trabalhador se mede pela quantificação de sua produção, número de artigos indexados com QUALIS/CAPES de estrato elevado e ainda dentro do "prazo de validade", pois esses mesmos artigos tem prazo de "esgotamento", três ou cinco anos. Após esse período o mesmo deixa de ser computado como "produção recente".

A intensificação do trabalho docente, segundo o padrão produtivista da lógica do capital, o coloca perante a competitividade própria do mercado capitalista. Para atender aos padrões de excelência e assim tentar preservar sua remuneração o trabalhador da educação priva-se do mínimo de existência digna, utilizando meios desconexos para atingir fins estranhos aos seus objetivos, até mesmo de realização pessoal. Segundo Giovanni Alves:

\begin{abstract}
A vida reduzida também é vida enxuta, na medida em que a vida das pessoas humanas tende a reduzir às partes necessárias à 'montagem' das exigências sistêmicas. No modo vida just-in-time, o tempo de vida disponível se reduziu a tempo de trabalho (e consumo) estranhado. $O$ sentido da instrumentalidade se impõe àqueles que organizam o seu tempo disponível: 'Eu faço não o que me dá fruição de vida, mas sim, o que tem utilidade para minha carreira profissional'. O tempo de vida é reduzido às atividades necessárias à carreira profissional e aos requerimentos alienados de consumo e status social. (ALVES, 2014, p. 18, grifo do autor)
\end{abstract}

A proletarização extrema do trabalhador da educação é mais perceptível entre aqueles submetidos ao contrato de trabalho de dedicação exclusiva, ou seja, o docente "quarenta horas" semanais, presente em sua maioria nas instituições públicas de ensino superior. No caso das instituições privadas de ensino superior, o regime de trabalho é ainda mais exaustivo e as relações contratuais ainda mais flexíveis. Embora a legislação trabalhista vigente defina claramente a questão da jornada de trabalho do trabalhador da educação:

Um dos aspectos relevantes contidos na CLT é condizente a carga horária a que estão sujeitos os professores, no qual, em atenção ao artigo 318, não poderá ministrar mais de quatro horas consecutivas, nem seis intercaladas, num mesmo estabelecimento, porém nada impede que o professor trabalhe em mais de um estabelecimento de ensino [...]. (OLIVEIRA, 2014, p. 80).

Além da Consolidação das Leis do Trabalho - CLT, é possível definir as condições contratuais do professor horista por meio de acordos ou convenções coletivas, que acabam servindo de suporte para uma regulamentação dessa categoria de trabalho, inclusive definindo o valor da hora-aula e a atribuição ou não de hora atividade para a preparação das aulas, correção de provas e trabalhos, geralmente corresponde a $5 \%$ do valor da somatória das horas aula ministradas.

Esse é o contexto do denominado "docente horista", ou seja, os trabalhadores da educação que são remunerados segundo a carga horária atribuída pela IES, ou seja, ganha por aula ministrada, a chamada "hora-aula". Em razão de não ter uma carga horária "fechada", o docente horista não se enquadra no regime parcial (20 horas) ou dedicação exclusiva (40 horas).

$\mathrm{Na}$ atualidade, embora haja uma tendência para reduzir esse número, o docente horista representa quase $60 \%$ do total de docentes do ensino superior. No ano de 2007 chegou a $85 \%$ do total de 140.000 docentes do ensino superior. Houve uma redução considerável durante o período de 2007 (120.000) a 2013 (80.000), mas tal fato não inviabiliza a constatação da precariedade dessa categoria de trabalho que, somada ao tempo parcial, representa a maioria esmagadora dos docentes do ensino superior no país. (CENSO DO ENSINO SUPERIOR, 2013). Contrariando a própria LDB que determina o mínimo aceitável de contratação de docente horista em uma instituição de ensino superior. 
Segundo Bosi:

Em relação à legislação educacional que estabeleceu parâmetros de contratação já bastante flexíveis a partir de 1996 (LDB), 7 das 84 universidades públicas não cumprem a exigência de terem pelo menos um terço do corpo docente em regime de tempo integral. Já entre as universidades privadas, esse tipo de transgressão atinge 65 das 86 IES existentes, o que representa mais de $75 \%$ numa situação ilegal. BOSI, 2007, p. 1509).

Condicionado à oferta de aulas em mais de uma instituição de ensino, para compor seu salário, o docente horista geralmente ministra aulas em duas ou três instituições e acaba trabalhando nos três períodos, em detrimento de sua saúde física e emocional. Segundo estudiosos tal contexto contribui para o fenômeno denominado síndrome de burnout, um estado de absoluto estresse ocupacional. Segundo Carlotto:

As frustrações emocionais peculiares a este fenômeno podem levar a sintomas psicossomáticos como insônia, úlceras, dores de cabeça e hipertensão, além de abuso no uso de álcool e medicamentos, incrementando problemas familiares e conflitos sociais. Nos aspectos profissionais, o professor pode apresentar prejuízos em seu planejamento de aula, tornando-se este menos frequente e cuidadoso. Apresenta perda de entusiasmo e criatividade, sentindo menos simpatia pelos alunos e menos otimismo quanto à avaliação de seu futuro. (CARLOTO, 2002).

No contexto da precarização do trabalho docente surgem novas determinações ao exercício de suas funções. Embora com a depreciação salarial, condições indignas de trabalho e flexibilidade na regulamentação de suas atividades, o docente universitário deve:

1) Apresentar uma aula "criativa", com a utilização de multimídia, com o objetivo de "prender" a atenção de mais de cem alunos em apenas uma sala.

2) Ser produtivo, publicar artigos em periódicos com classificação QUALIS/CAPES, além de apresentar bons resultados nos indicadores de produção da Plataforma Lattes.

3) Em razão da evolução tecnológica exercer atividades antes destinadas às secretarias das instituições de ensino superior, como lançar notas e faltas.

Se por um lado a qualificação dos trabalhadores foi colocada como exigência neste novo mercado e tem havido o incentivo governamental para ampliação do ensino superior público e privado, por outro se verifica a intensificação e precarização do trabalho docente.

\section{4 | CONCLUSÃO}

A precarização do trabalho do docente do ensino superior torna-se evidente quando reconhecemos o contexto da otimização do trabalho dessa categoria específica, ou seja, incentivos governamentais, aumento do número de matrículas, aumento da proporção alunos/professor, aumento da carga horária para suprir a depreciação salarial - decorrente da flexibilização trabalhista - e consequentes formas "criativas" e também depreciativas de contrato de trabalho.

A intensificação do trabalho do docente do ensino superior estende-se também a natureza de seu trabalho, ou seja, os resultados esperados indicam claramente o "quanto" esse profissional produz. Nesse contexto, a qualidade do trabalho docente universitário se expressa por meio da quantidade de produção, ou seja, quantas aulas ministradas, orientações concluídas e em andamento, publicações, dentre outras determinações de caráter quantitativo. 
O cotidiano do trabalhador do ensino superior expressa claramente a preocupação com a qualificação profissional, sendo plenamente justificável, pois essa é a condição para se manter inserido no mercado de trabalho.

Todas as dificuldades encontradas pelo docente universitário, tendo em vista as transformações decorrentes do contexto "globalizado" e da reestruturação produtiva do capital, são agravadas quando a categoria de trabalho é o docente "horista", em razão da própria natureza de sua ocupação. 


\section{Referências}

ALVES, Giovanni. Dimensões da reestruturação produtiva: ensaios de Sociologia do Trabalho. 2.ed., Londrina: Praxis, 2007.

Trabalho e neodesenvolvimentismo: Choque de capitalismo e nova degradação do trabalho no Brasil. Bauru: Praxis, 2014.

Trabalho e mundialização do capital: a nova degradação do trabalho na era da globalização. São Paulo: Praxis, 1999, p. 169.

ANTUNES, Ricardo. Adeus ao trabalho? Ensaio sobre as metamorfoses e a centralidade do mundo do trabalho. São Paulo: Cortez, 1999.

BOSI, Antônio de Pádua. A Precarização do trabalho docente nas instituições de ensino superior do Brasil nesses últimos 25 anos. Educação e Sociedade. Campinas, vol. 28, n. 101, p. 1503-1523, set./dez. 2007. Disponível em http://www.cedes.unicamp.br. Acesso em 06 jul 2015.

CARLOTTO, Mary Sandra. A síndrome de burnout e o trabalho docente. Psicologia em Estudo, Maringá, v. 7, n. 1, p. 21-29, jan./jun. 2002. Disponível em http://www.scielo. br/pdf/pe/v7n1/v7n1a03.pdf. Acesso em 07 de julho 2015.

CENSO DA EDUCAÇÃO SUPERIOR. MEC/IPEA, 2013. Disponível em http://download.inep.gov.br/educacao_ superior/censo_superior/apresentacao/2014/coletiva censo_superior_2013.pdf. Acesso em 20 de maio 2015.

FIES - CENSO DA EDUCAÇÃO SUPERIOR E A EVOLUÇÃO DO FUNDO DE FINANCIAMENTO ESTUDANTIL. Disponível em http://download.inep.gov.br/ educacao_superior/censo_superior/encontro_nacional/2013/palestra_censo_educacao_superior_evolucao do_fundo_de_financiamento_estudantil.pdf. Acesso em 20 maio 2015.
FRIGOTTO, Gaudêncio. Os delírios da razão: crise do capital e metamorfose conceitual no campo educacional. In: GENTILI, Pablo (Org.). Pedagogia da exclusão: crítica ao neoliberalismo em educação. Petrópolis: Vozes, 1997.

OLIVEIRA, Lourival José de; PIRES, Ana Paula Vicente. Da precarização do trabalho docente no Brasil e o processo de reestruturação produtiva. Revista do Direito Público, Londrina, v. 9, n. 1, p.73-100, jan./abr.2014.

PLATAFORMA LATTES. Disponível em http://lattes. cnpq.br/. Acesso em 19 jul 2015.

PORTAL PROUNI. Disponível em http://prouniportal. mec.gov.br/images/pdf/Quadros_informativos/numero_ bolsas_ofertadas_por_uf_segundo_semestre_2014. pdf. Acesso em 06 jul 2015.

PROGRAMA CIÊNCIA SEM FRONTEIRAS. Governo Federal. Distribuição de bolsas implementadas por área prioritária. Disponível em <http://www.cienciasemfronteiras.gov.br/web/csf/painel-de-controle>, acesso 29 abril, 2015.

Programa Ciência sem Fronteiras. Governo Federal. Disponível em http://www.cienciasemfronteiras.gov.br/web/ csf/oprograma;jsessionid=BD46B23E132298A59A46DBCEDDB3C1E0, acesso 01 maio 2015. 